\title{
OPEN Visual marking in mammals first proved by manipulations of brown bear tree debarking
}

\author{
Vincenzo Penteriani ${ }^{1,8} \bowtie$, Enrique González-Bernardo ${ }^{1,2,8}$, Alfonso Hartasánchez ${ }^{3}$, \\ Héctor Ruiz-Villar ${ }^{1}$, Ana Morales-González ${ }^{4}$, Andrés Ordiz ${ }^{5}$, Giulia Bombieri', \\ Juan Diaz García7, David Cañedo ${ }^{7}$, Chiara Bettega ${ }^{1}$ \& María Del Mar Delgado ${ }^{1}$
}

The rather limited human ability to understand animal vision and visual signalling has frequently clouded our expectations concerning the visual abilities of other animals. But there are multiple reasons to suspect that visual signalling is more widely employed by animals than previously thought. Because visibility of visual marks depends on the background in which they are seen, species spending most of their time living in dark conditions (e.g., in forests and/or having crepuscular and nocturnal habits) may rely on bright signals to enhance visual display. Here, as a result of experimental manipulations, we present, for the first time ever, evidence supporting the use of a new channel of intraspecific communication by a mammal species, i.e., brown bear Ursus arctos adult males relying on visual marks during mating. Bear reactions to our manipulation suggest that visual signalling could represent a widely overlooked mechanism in mammal communication, which may be more broadly employed than was previously thought.

Among the many groups of terrestrial species, our understanding of mammal visual signalling might be hampered by the fact that most research on mammals has focused on chemical (e.g., scat, urine, and glands) and acoustic (e.g., howling) signalling ${ }^{1,2}$. Instead ${ }^{2,3}$, visual communication might be an overlooked communication channel $^{2,4}$, despite being perhaps as important as the others, if we consider that: (1) mammal coloration has evolved for inter- and intraspecific communication ${ }^{2,4-7}$, which means that mammals use visual signals to communicate; and (2) visual signalling through physical marks (e.g., bites and scratches) is permanent and, thus, has the obvious advantages of (a) being long-lasting, i.e., environmental factors such as rain or snow are less likely to affect the detectability of visual marks as compared to, e.g., chemical signalling ${ }^{8}$, although mammals have found strategies to make chemical signalling last as long as possible ${ }^{9}$, and (b) functioning remotely, i.e., even when the signaller is away from the marked location ${ }^{2}$. Visual marking may also allow individuals to reduce repeated visits to strategic marking points, and thus save time and energy, which would otherwise detract animals from other activities, like foraging and reproduction ${ }^{10}$. Therefore, visual signalling may represent a reliable and advantageous communication channel ${ }^{8}$.

Solitary species like bears may benefit from advertising their location, size, and reproductive status to expedite mate selection during the breeding season. Moreover, brown bears usually occur at low densities across their range, making direct interactions with one another infrequent ${ }^{11,12}$. Thus, long-lasting visual signalling may be particularly effective and considerably time saving. To date, studies on bear communication have highlighted two main forms of communication ${ }^{10,13-17}$ : (1) olfactory communication, i.e., the marking of focal trees by rubbing the body against the trunk and/or by urination and deposition of anogenital gland secretions; and (2) pedal marking, by which bears mark the ground with their scent by grinding their feet into the substrate. Auditory communication, e.g., vocalizations used as threats during agonistic encounters, to advertise sexual receptivity, or for communication between females and their cubs, is considered as the least important channel through

${ }^{1}$ Research Unit of Biodiversity (UMIB, CSIC-UO-PA), Mieres Campus, 33600 Mieres, Spain. ${ }^{2}$ Pyrenean Institute of Ecology (IPE), C.S.I.C., Avda. Montañana 1005, 50059 Zaragoza, Spain. ${ }^{3}$ FAPAS Fondo para la Protección de los Animales Salvajes, Ctra. AS-228, km 8,9 - Tuñón, 33115 Santo Adriano, Asturias, Spain. ${ }^{4}$ Department of Conservation Biology, Estación Biológica de Doñana, C.S.I.C, Avda. Americo Vespucio 26, 41092 Sevilla, Spain. ${ }^{5}$ Faculty of Environmental Sciences and Natural Resource Management, Norwegian University of Life Sciences, Postbox 5003, NO-1432, Ås, Norway. ${ }^{6}$ MUSE - Museo delle Scienze, Sezione Zoologia dei Vertebrati, Corso del Lavoro e della Scienza 3, 38123 Trento, Italy. ${ }^{7}$ Consejería de Ordenación del Territorio, Infraestructuras y Medio Ambiente, Dirección General de Biodiversidad, Oviedo, Principado de Asturias, Spain. ${ }^{8}$ These authors contributed equally: Vincenzo Penteriani and Enrique González-Bernardo. ${ }^{\square}$ email: v.penteriani@csic.es 

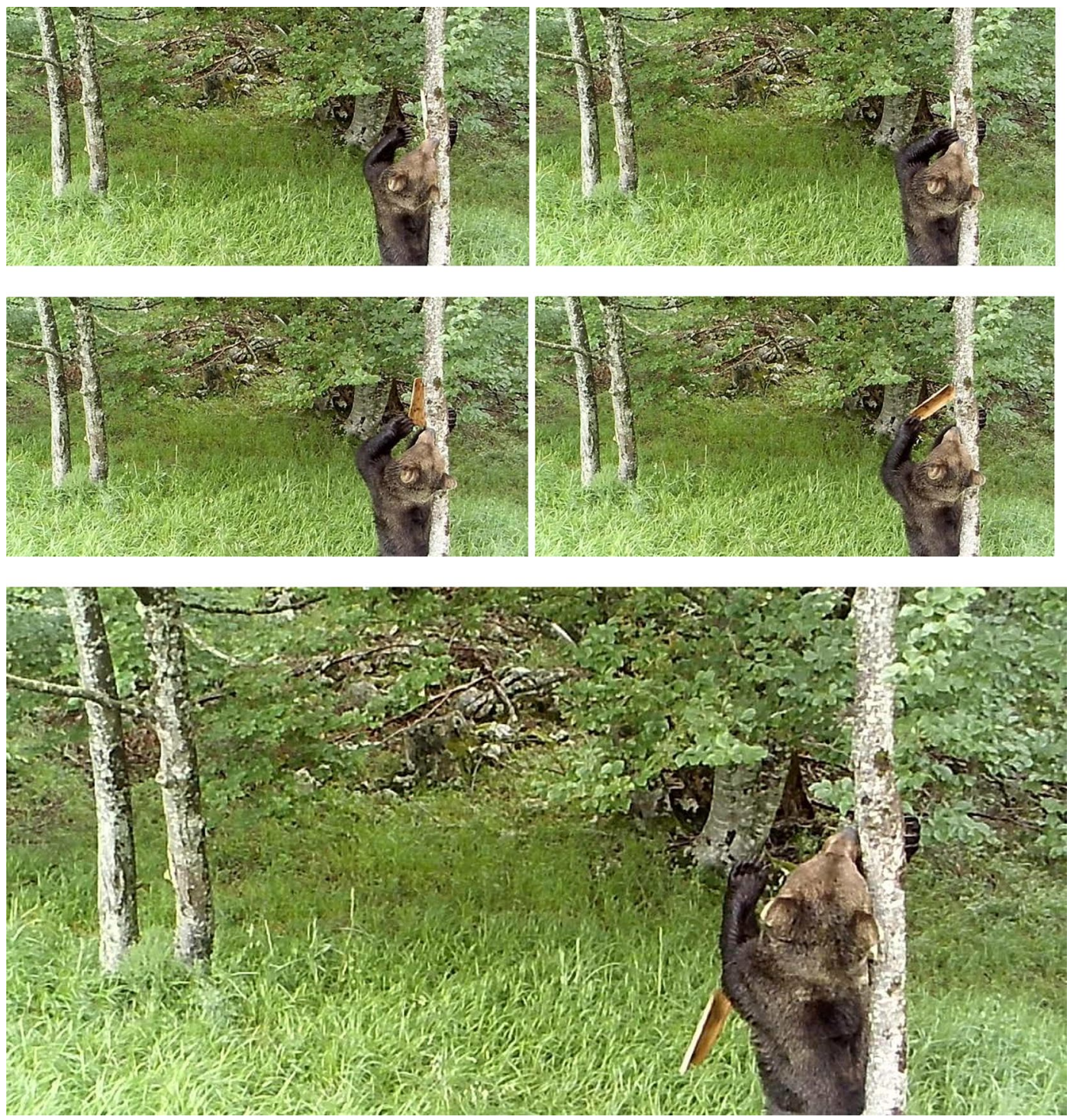

Figure 1. Brown bear response to trunk mark manipulation. The behavioural sequence of an adult male brown bear removing the pieces of bark that we used to conceal the visual markings on an ash tree during the mating season in the Cantabrian Mountains, Spain $(12 / 06 / 2020,15 \mathrm{~h} 37)$. The whole sequence is shown in the video footage Extended Data Fig. 5.

which bears signal, whereas visual communication has always been considered limited to different forms of body postures or behavioural displays (but $\operatorname{see}^{18}$ ).

Since the beginning of the 1980 s, bear marks on trees have puzzled researchers ${ }^{8}$. The function of, and motivation behind, tree biting and clawing have prompted a variety of theories related to glandular scent deposition (i.e., chemical signalling), but none of these hypotheses has been considered satisfactory, nor have they ever been tested $^{8}$. The debarking behaviour of brown bears Ursus arctos, which leaves bright and conspicuous marks on tree trunks (see Extended Data Fig. 1 and Extended Data Fig. 2), presents a unique yet unexplored opportunity to investigate new ways of visual communication in terrestrial mammals, and to better understand both bear and carnivore communication broadly. The hypothesis behind this experimental work is that brown bears may rely on visual communication via the conspicuous marks that they produce on trees.

After manipulating bear tree marks in the Cantabrian Mountains (north-western Spain), we found that bears removed the bark strips that we used to cover their marks during the mating season (Extended Data Figs. 3 and 4), suggesting that bear debarking may represent a visual communication channel used for intraspecific communication.

Brown bear responses to marked tree manipulations. After concealing bear marks due to trunk debarking with bark strips from the same tree species (see "Methods"), our manipulations on 20 trees triggered a rapid reaction from brown bears. Between the 16th of May and the end of September 2020 (overlapping part of the brown bear mating period in the Cantabrian Mountains ${ }^{19}$ ), brown bears removed the strips of bark that we used to cover the trunk marks in 9 (45\%) out of the 20 manipulated trunks (Fig. 1 and Extended Data Fig. 5). 
However, if we consider that these nine trees were also the ones that we could manipulate (because of field work restrictions due to COVID-19) from the start of the mating season (beginning of May), $100 \%$ of the bark strips used to cover tree marks were removed by bears when the manipulation occurred at the commencement of the mating season. In only one case, a bear removed the bark strips covering marks on a tree that was manipulated later in the mating season (end of June). Control bark strips fixed to (a) the same trunk as the manipulated bear mark, (b) the nearest neighbouring tree to the manipulated one showing bear marks, and (c) the nearest rubbing trees with no bear marks, were never removed by bears. In two cases (50\%), after the first removal of the manipulated mark by a bear, which was subsequently covered again with new strips $(n=4)$, a bear removed the strips a second time. Further, camera traps showed that: (1) bears uncovered the manipulated marks the first time they visited the tree after our manipulation; (2) bark strips that were not removed were always the result of bears not visiting the site after tree manipulations; and (3) the shortest lapse of time between a mark manipulation and a bear visiting the tree for the first time and uncovering the mark was seven days. Thus, manipulations always triggered a rapid response from bears when adult males, probably the same individuals that debarked the trunks, came back and check on marked trees.

Conspicuousness of brown bear visual marks. The conspicuousness of a visual signal is not only increased by its position in a noticeable location, but also by the contrast between the signal and its background ${ }^{20,21}$. A remarkable difference (pixel intensity: mean $( \pm S D)=85.09 \pm 26.77$, range $=20.27-177.06$ ) exists between bark and sapwood brightness for all tree species $(t=19.07, p=<2.2 \mathrm{e}-16)$ (Extended Data Fig. 1). Even if contrast values for certain tree species, such as linden Tilia platyphyllos $(p=0.05)$ and hazel Corylus avellana $(p=0.09)$, were considerably higher than those for the rest of the species, the debarked tree species showed no remarkable differences in contrast among them $\left(F=1.11, p=0.39, \mathrm{R}^{2}=0.03\right)$, which suggests that a debarked tree is always conspicuous, independent of bark colour.

Tree species selection for marking purposes. Debarked trees belonged to species relatively scarce in forest stands, i.e., only $31.1 \% \pm 29.4$ of the trees recorded in the proximity of a marked tree (see "Tree species selection for marking purpose" in "Methods") were of the same species as the trees marked by bears. Moreover, in only 19 of the 59 covered transects $(33.90 \%)$, the tree species marked by bears was the most abundant one. These percentages decrease if we remove a single monospecific forest stand of planted Monterey pine Pinus radiata. Indeed, if we only take into account native forest stands: (a) only $26.2 \% \pm 26.2$ (range $=0-85.7 \%$ ) of the trees recorded in the proximity of the marked tree corresponded to the same species as the tree marked by a bear; and (b) in only $26.4 \%$ of transects, the tree species marked by bears was the most abundant one. This suggests that bears may select for some tree species, probably because of the characteristics of their bark, e.g., softness ${ }^{22}$.

Dominant males use chemical signalling to communicate and maintain dominance over other males and, consequently, subordinate males have been shown to scent-mark less than dominant males and in some cases not scent-mark at all ${ }^{14-16}$. Our two-year video recordings (Extended Data Figs. 3, 4 and 7) show analogies between chemical and visual signalling, the latter being also mainly performed by adult males during the mating season.

Interestingly, clawing and biting the bark of a tree, often leaving fur, frayed bark and scars on the tree trunk or other substrates, have always been considered olfactory signals ${ }^{10,23}$. For example, it has been suggested that clawing may leave scent from pedal glands and biting may deposit saliva ${ }^{10}$. Yet, at least for brown bears, the amount of smell left by scratches and bite marks on trees is expected to be less than that left by secretions from sebaceous and apocrine glands when rubbing the whole body ${ }^{10}$ and, thus, might result in an unnecessary reinforcement of body rubbing. Moreover, visual marks are generally on the upper sections of the tree, which can only be reached by larger adult males, and furthermore they would not be reached while body rubbing (Extended Data Fig. 9). This may explain why adult males use multiple marking behaviours to leave two different signals, i.e., chemical and visual, which may complement each other ${ }^{8}$. For example, whereas a chemical signal provides information on bear sex and individuality, visual marks might simultaneously indicate the height of the bear, thus providing a signal that is physically associated with a quality of interest to the receiver ${ }^{24}$. A similar behaviour has been suggested for tigers, Panthera tigris, which mark their territories by scratching as high as they can on tree trunks, a signal physically connected to their size ${ }^{25}$. It has also been hypothesised that visual marks simply identify the location of chemical signalling ${ }^{8}$. However, we believe that this may not always be the case, since: (1) visual marks do not necessarily happen on trees where body rubbing and pedal marking occur (Extended Data Figs. 1 and 8); and (2) a visual mark on a tree in a forest is only visible when the receiver is close to the mark, whereas chemical signals may go farer (e.g. by wind action) and reach an animal before a visual one.

Our results suggest that trunk debarking by brown bears plays an important role in visual communication at least during the mating season. In turn, visual signalling may be related to individual fitness, because communication is the first step towards successful mating and eventual reproduction.

This is the first time, to our knowledge, that the active role of visual marking in a mammalian species was experimentally tested in the field. To conclude, bear reactions to our manipulation suggest that visual signalling could represent a widely overlooked mechanism in mammal communication, which may be more broadly employed than was previously thought.

\section{Methods}

Manipulation of trunk debarking. Twenty trees with brown bear marks on their trunks ${ }^{26}$ were used for bark manipulations from the 1st of May 2020 (the beginning of the mating period in the Cantabrian Mountains ${ }^{19}$ ) to the end of September 2020 (the beginning of the hyperphagia period in this area ${ }^{19}$, when trunk marking is supposed to stop or, at least, to decrease ${ }^{8}$ ). Strips of bark of the same species as the marked trees were used to cover bear marks (Extended Data Fig. 6). We collected strips from the ground or we debarked a distant 
(preferably recently died) tree to avoid any further interaction with the trees marked by bears. Control bark strips were used on: (a) the same trunks as the manipulated bear marks, (b) the nearest tree of the same species as the manipulated one, and (c) the nearest rubbing trees with no bear marks. Control strips were used to discard the possibility that brown bears were attracted by our scent and removed the strips for any reason other than to uncover their visual marks. Additionally, in four cases where a bear removed the mark manipulation, it was possible to cover the bear mark again to reinforce support for the importance of visual signalling in brown bears. All manipulated trees were checked approximately every 15 days.

In five of the manipulated trees camera, traps were deployed (Browning Dark Ops HDProX) from May to August 2020. This period has been considered the one in which debarking is most intense in bears ${ }^{8}$. Camera traps were programmed to record, when triggered by an animal, one-minute videos during the day, and 20-s videos at night, with a one-second trigger delay between videos. All sites were visited every two weeks to check if the bark manipulations had been removed and to service camera traps (e.g. battery check, eventually stolen cameras). Additionally, to document brown bear debarking behaviour away from of our manipulations, from January 2019 to July 2020 six additional camera traps were deployed to monitor six previously known rubbing trees highly frequented by bears, but where no visual marks were found (e.g., Extended Data Fig. 3).

Conspicuousness of brown bear visual marks. To explore the possibility that brown bear tree marking is a conspicuous signal on a trunk, we measured the contrast between the barkand sapwood for each of the marked tree species, as a proxy of mark brightness and conspicuousness. Using a blade, we first removed a small section of bark (approximately $3 \times 4 \mathrm{~cm}$, outer and inner bark) from three different trunks for each tree species. Bark removal exposed the sapwood, as happens in brown bear debarking. We took a total of 36 tree photos (JPEG format, $7 \mathrm{MG}$ each), corresponding to 3 individuals from each of the 12 tree species where visual marking was detected: sycamore maple Acer pseudoplatanus, hazel Corylus avellana, birch Betula pubescens, chestnut Castanea sativa, cherry Prunus avium, ash Fraxinus excelsior, beech Fagus sylvatica, whitebeam Sorbus aria, Monterey pine Pinus radiata, oak Quercus petraea, willow Salix caprea, and linden Tilia platyphyllos. For repeatability purposes ${ }^{18,27}$, we took six measurements of bark brightness (three measurements of the bark and three of the exposed sapwood) for each picture. Finally, we calculated mean brightness values for both the cortex and the sapwood, and afterwards we calculated the contrast value (i.e., brightness of the bark - brightness of the sapwood) for each picture, for statistical purposes. Brightness values were obtained by processing the images with the Java-based image processing program ImageJ (https://imagej.nih.gov/ij/), by means of the Oval Selection Tool (width $=200$ pixels, height $=200$ pixels) and the Measure Tool. Digital images are two-dimensional grids of pixel intensity values with the width and height of the image being defined by the number of pixels in $\mathrm{x}$ (rows) and y (columns) directions. Thus, pixels (picture elements) are the smallest single component of digital images, holding numeric values (pixel intensities) that range between black and white. RGB pixels are converted to brightness values using the formula $=($ red + green + blue) $/ 3$ (ImageJ User Guide IJ 1.46r, http://imagej.nih. gov/ij/docs/guide).

Tree species selection for marking purposes. To study whether brown bears might select specific trees on which to leave visual marks because, e.g., of the conspicuousness of the mark and/or the ease of debarking, we used a set of 59 debarked trees previously recorded in the Cantabrian Mountains ${ }^{26}$ to walk 59 linear transects with the aim of comparing the frequency of the tree species debarked by bears $v s$. the abundance of each tree species around the marked tree. Each transect had a total length of $40 \mathrm{~m}(20 \mathrm{~m}$ up and $20 \mathrm{~m}$ down from the marked tree), and the total number of trees of each species was recorded. The mean $( \pm$ SD) number of trees (all species together) recorded was $13.0 \pm 6.7$ (range $=1-30$ trees).

Statistical analyses. We first compared the average brightness of bark with the average brightness of sapwood ( $n=36$ pictures) using a paired $t$-test $(\alpha=0.05)$. Second, to assess the variation in contrast among tree species, we built a linear model with contrast as the response variable, and species as the explanatory variable. Analyses were performed in R 3.5.1 statistical software ${ }^{28}$.

Received: 19 January 2021; Accepted: 5 April 2021

Published online: 04 May 2021

\section{References}

1. Warrant, E. Vision in the dimmest habitats on Earth. J. Comp. Physiol. A. 190, 765-789 (2004).

2. Penteriani, V. \& Delgado, M. M. Living in the dark does not mean a blind life: Bird and mammal visual communication in dim light. Philos. Trans. R. Soc. B Biol. Sci. 372, 20160064. https://doi.org/10.1098/rstb.2016.0064 (2017).

3. Marchetti, K. Dark habitats and bright birds illustrate the role of the environment in species divergence. Nature 362, 149-152 (1993).

4. Caro, T., Walker, H., Santana, S. E. \& Stankowich, T. The evolution of anterior coloration in carnivorans. Behav. Ecol. Sociobiol. 71, 177 (2017)

5. Caro, T. Contrasting colouration in terrestrial mammals. Philos. Trans. R. Soc. B 364, 537-548 (2009).

6. Caro, T. \& Mallarino, R. Coloration in mammals. Trends Ecol. Evol. 35, 357-366 (2020).

7. Moreira, L. A. A., Duytschaever, G., Higham, J. P. \& Melin, A. D. Platyrrhine color signals: new horizons to pursue. Evol. Anthropol. 28, 236-248 (2019).

8. Burst, T. L. \& Pelton, M. R. Black Bear Mark Trees in the Smoky Mountains. in Fifth International Conference on Bear Research and Management 5, 45-53 (1983) 
9. Mohorović, M. \& Krofel, M. The scent world of cats: where to place a urine scent mark to increase signal persistence?. Anim. Biol. $1,1-18(2020)$

10. Gehring, J. Bear Communication. In Encyclopedia of Animal Cognition and Behavior (eds. Vonk, J. \& Shackelford, T.) (Springer, 2018).

11. Steyaert, S. M. J. G., Endrestøl, A., Hackländer, K., Swenson, J. E. \& Zedrosser, A. The mating system of the brown bear Ursus arctos. Mamm. Rev. 42, 12-34 (2012).

12. Swenson, J. E. et al. Brown bear (Ursus arctos Linnaeus, 1758). In Bears of the World: Ecology, Conservation and Management (eds. Penteriani, V. \& Melletti, M.) (Cambridge University Press, 2020).

13. Sergiel, A. et al. Histological, chemical and behavioural evidence of pedal communication in brown bears. Sci. Rep. 7, 1-10 (2017).

14. Lamb, C. T. et al. Density-dependent signaling: an alternative hypothesis on the function of chemical signaling in a non-territorial solitary carnivore. PLoS ONE 12, 1-12 (2017).

15. Clapham, M., Nevin, O. T., Ramsey, A. D. \& Rosell, F. Scent-marking investment and motor patterns are affected by the age and sex of wild brown bears. Anim. Behav. 94, 107-116 (2014).

16. Clapham, M., Nevin, O. T., Ramsey, A. D. \& Rosell, F. The function of strategic tree selectivity in the chemical signalling ofbrown bears. Anim. Behav. 85, 1351-1357 (2013).

17. Revilla, E. et al. Brown bear communication hubs: patterns and correlates of tree rubbing and pedal marking at a long-term marking site. PeerJ 9, e10447 (2021).

18. Penteriani, V. et al. Characteristics of sun bear chest marks and their patterns of individual variation. Ursus 31, e19 (2020).

19. Martínez Cano, I., González Taboada, F., Naves, J., Fernández-Gil, A. \& Wiegand, T. Decline and recovery of a large carnivore: environmental change and long- term trends in an endangered brown bear population. Proc. R. Soc. B 283, 20161832 (2016).

20. Rosenthal, G. \& Ryan, M. Visual and acoustic communication in non-human animals: a comparison. J. Biosci. 25, 285-290 (2000).

21. Bradbury, J. W. \& Vehrencamp, S. Principles of Animal Communication (Sinauer Associates, 2011).

22. Richter, C. Wood Characteristics (Springer International Publishing, 2015).

23. Cornhill, K. L. \& Kerley, G. I. H. Cheetah behaviour at scent-marking sites indicates differential use by sex and social rank. Ethology 126, 976-986 (2020).

24. Maynard Smith, J. \& Harper, D. G. C. Animal signals: models and terminology. J. Theor. Biol. 177, 305-311 (1995).

25. Thapar, V. Tigers: Portrait of a Predator (Collins, 1986).

26. González-Bernardo, E. et al. Rubbing behaviour of European brown bears: factors affecting rub tree selectivity and density. J. Mammal. (2021)

27. Penteriani, V., Alonso-Alvarez, C., Delgado, M. M., Sergio, F. \& Ferrer, M. Brightness variability in the white badge of the eagle owl Bubo bubo. J. Avian Biol. 37, 110-116 (2006).

28. R Development Core Team. R: A Language and Environment for Statistical Computing. R Foundation for Statistical Computing, Vienna. https://www.r-project.org. https://www.R-project.org (2016).

\section{Acknowledgements}

V.P. and A.O. were financially supported by an Excellence Project (CGL2017-82782-P) financed by the Spanish Ministry of Science, Innovation and Universities, the Agencia Estatal de Investigación (AEI) and the Fondo Europeo de Desarrollo Regional (FEDER, EU). V.P. was also financially supported by a GRUPIN research grant from the Regional Government of Asturias (IDI/2018/000151). M.M.D. was financially supported by a Spanish Ramon y Cajal grant RYC-2014-16263. G.B. was financially supported by a post-doctoral research contract from MUSE - Museo delle Scienze di Trento (Italy). Stephanie Wentworth, Customer Service Agent of Browning Trail Camera Tech Support, helped us to solve logistical and technical issues with camera traps. The local administrations of Junta de Castilla y León and Principado de Asturias gave us the authorisations needed to work in the brown bear restricted areas of the Cantabrian Mountains. Special thanks to Fernando Rubiera González and Estrella Fernández Martínez (Instituto de Ciencia y Tecnología del Carbono, INCAR-CSIC), and Yolanda Pueyo Estaún (Instituto Pirenaico de Ecología, IPE-CSIC), for providing the permissions needed to continue field work during the COVID-19 state of emergency confinement.

\section{Author contributions}

V.P. conceived the study and supervised the project. All authors designed the experiment. V.P., E.G.-B., A.H., H.R.-V., A.M.-G., A.O, D.C., J.D.G. and M.M.D performed field manipulations. V.P., E.G.-B. and M.M.D. analysed data. V.P. wrote the paper with the support of E.G.-B. and M.M.D. All authors discussed the results and implications and commented on the manuscript at all stages.

\section{Competing interests}

The authors declare no competing interests.

\section{Additional information}

Supplementary Information The online version contains supplementary material available at https:/doi.org/ 10.1038/s41598-021-88472-5.

Correspondence and requests for materials should be addressed to V.P.

Reprints and permissions information is available at www.nature.com/reprints.

Publisher's note Springer Nature remains neutral with regard to jurisdictional claims in published maps and institutional affiliations. 
(c) (i) Open Access This article is licensed under a Creative Commons Attribution 4.0 International cc) License, which permits use, sharing, adaptation, distribution and reproduction in any medium or format, as long as you give appropriate credit to the original author(s) and the source, provide a link to the Creative Commons licence, and indicate if changes were made. The images or other third party material in this article are included in the article's Creative Commons licence, unless indicated otherwise in a credit line to the material. If material is not included in the article's Creative Commons licence and your intended use is not permitted by statutory regulation or exceeds the permitted use, you will need to obtain permission directly from the copyright holder. To view a copy of this licence, visit http://creativecommons.org/licenses/by/4.0/.

(C) The Author(s) 2021 